\title{
Bleeding Duodenal Diverticulum with Iatrogenic Perforated Duodenal Diverticulum: Double Trouble
}

\author{
Mohd A H $\mathbf{H}^{1}$, Sarmukh Singh ${ }^{2 *}$, Azmi H $^{2}$ \\ ${ }^{1}$ Department of General Surgery, International Islamic University Malaysia. \\ ${ }^{2}$ Department of General Surgery, Sultan Haji Ahmad Shah Hospital, Malaysia.
}

*Corresponding Author: Sarmukh Singh, Department of General Surgery, Sultan Haji Ahmad Shah Hospital, Malaysia.

Received Date: 30 July 2021 | Accepted Date: 14 September 2021 | Published Date: 17 September 2021

Citation: Mohd A H, S Singh, Azmi H. (2021). Bleeding Duodenal Diverticulum with Iatrogenic Perforated Duodenal Diverticulum: Double Trouble. Journal of Clinical Surgery and Research; 2(5); DOI: 10.31579/2768-2757/026

Copyright: (C2021 Sarmukh Singh, This is an open-access article distributed under the terms of the Creative Commons Attribution License, which permits unrestricted use, distribution, and reproduction in any medium, provided the original author and source are credited.

\begin{abstract}
Background: Duodenal diverticulum is the second most common location following the large bowel. Only 1-5\% of patients with DD are symptomatic. Complications of duodenal diverticulum includes obstruction of duodenum, biliary pancreatic duct, pancreatitis, haemorrhage, diverticulitis with or without perforation, and other biliopancreatic manifestations including fistula formation in the bile duct, choledocholithiasis and cholangitis, bezoar formation inside the diverticulum, perforation and bleeding. Surgical or non-surgical treatment are considered in selected patient in treating perforated duodenal diverticulum.

Case Presentation: We present a 69 year old gentleman presented to emergency department with complaint of passing out blackish stool for 2 days duration associated with presyncopal attack. On arrival, patient appear pale with class 3 hypovolemic shock symptoms. Abdominal examination revealed mild tenderness over epigastric region without signs of peritonism. Digital rectal examination showed fresh melena. Oesophagogastroduodenoscopy (OGDS) showed a huge diverticulum at duodenum (D3) with pooling of blood and blood clots. In view of bleeding at D3 diverticulum,adrenaline was injected and haemoclipped was applied. Hemostasis from bleeding duodenal diverticulum was successfuly secured. However, patient had iatrogenic perforated duodenal diverticulum.

Conclusion: We present a case of upper gastrointestinal bleeding from a D3 diverticulum with iatrogenic perforated duodenal diverticulum due to endoscopic hemostasisinjection. We treated this patient conservatively by keep nil by mouth and started on parentral nutritional support, intravenous antibiotics and serial abdominal examination. We advocate in duodenal diverticulum bleeding the application of endoscopic clips and injection should be use juridiously. In case of iatrogenic perforation of duodenum diverticulum due to endoscopic hemostasis can still be treated conservatively in stable, elderly patients with no signs of diffuse peritonitis and no clinical evidence of sepsis.
\end{abstract}

Keywords: duodenal diverticulum, perforation,upper gastrointestinal bleeding, endoscopic

\section{Introduction}

Duodenal diverticulum (DD) is the second most common location following the large bowel [1]. Commonest site for DD to occur is at second part of duodenum [2]. Duodenal diverticulum is commonly asymptomatic, only $1-5 \%$ of patients with duodenal diverticula become symptomatic [1]. Complications of DD are obstruction of duodenum, upper gastrointestinal bleeding, duodenal perforation, and very rare biliopancreatic manifestations such as fistula formation in the bile duct and cholangitis [3]. Upper gastrointestinal bleeding are rare but carries a high mortality rate up to $20 \%$ [1]. Perforated DD usually presents with acute onset of severe epigastric pain that radiates to the back or right shoulder. Computed Tomography (CT) Scan of abdomen is gold standard to diagnosis of perforated DD. Surgical treatment remain the main stay for perforated DD. However, it carries a high morbidity and mortality due to surgical complications such as, duodenal leak or fistula, abscess, iatrogenic injury to the common bile duct and acute pancreatitis [4]. Therefore, non-operative management can be considered in elderly patients with multiple comorbidities and without peritonitis [5]. We present a case of upper gastrointestinal bleeding from a D3 diverticulum with iatrogenic perforated duodenal diverticulum due to endoscopic hemostasisinjection. We treated this patient conservatively by keep nil by mouth and started on parentral nutritional support, intravenous antibiotics and serial abdominal examination. We advocate in duodenal diverticulum bleeding the application of endoscopic clips and injection should be use juridiously. In case of iatrogenic perforation due to endoscopic hemostasis can still be treated conservatively. 


\section{Case report:}

A 69 year old gentleman with underlying diabetes mellitus, presented to emergency department with complaint of passing out blackish stool for 2 days duration associated with presyncopalattack.On arrival, patient appear pale with class 3 hypovolemic shock (blood pressure 90/60 $\mathrm{mmHg}$, heart rate 120 beats/min). Abdominal examination revealed mild tenderness over epigastric region without signs of peritonism. Digital rectal examination showed fresh melena. Laboratory investigation showed low haemoglobin level is $6 \mathrm{~g} / \mathrm{dL}$ with acute kidney injury (urea $13.9 \mathrm{mmol} /$, creatinine $77 \mathrm{mmol} / \mathrm{L}$ ). Hypovolemic shock secondary to upper gastrointestinal bleeding. Oesophagogastroduodenoscopy (OGDS) performed and showed a huge diverticulum at duodenum (D3) with pooling of blood and blood clots (figure 1 and 2). In view of bleeding at
D3 diverticulum, adrenaline was injected and haemoclipped was applied. Hemostasis from bleeding duodenal diverticulum was successfuly secured. Post OGDS procedure, patient developed upper abdominal pain and upper back pain. Per abdomen examination noted localized tenderness over epigastric region with no peritonism. Proceeded with abdominal X-ray showed present of retroperitoneal free air (figure 3). We opted to treat this iatrogenic perforated duodenal diverticulum conservatively in view of patient elderly age and no sign of peritonism. Intravenous antibiotic (Ivcefoperazone $1 \mathrm{gm}$ twice daily and Iv metronidazole 500mg three times daily) was started. Patient was keep nil by mouth and started on parentral nutritional support. Patient was discharged home after completing 10 days course of intravenous antibiotics.

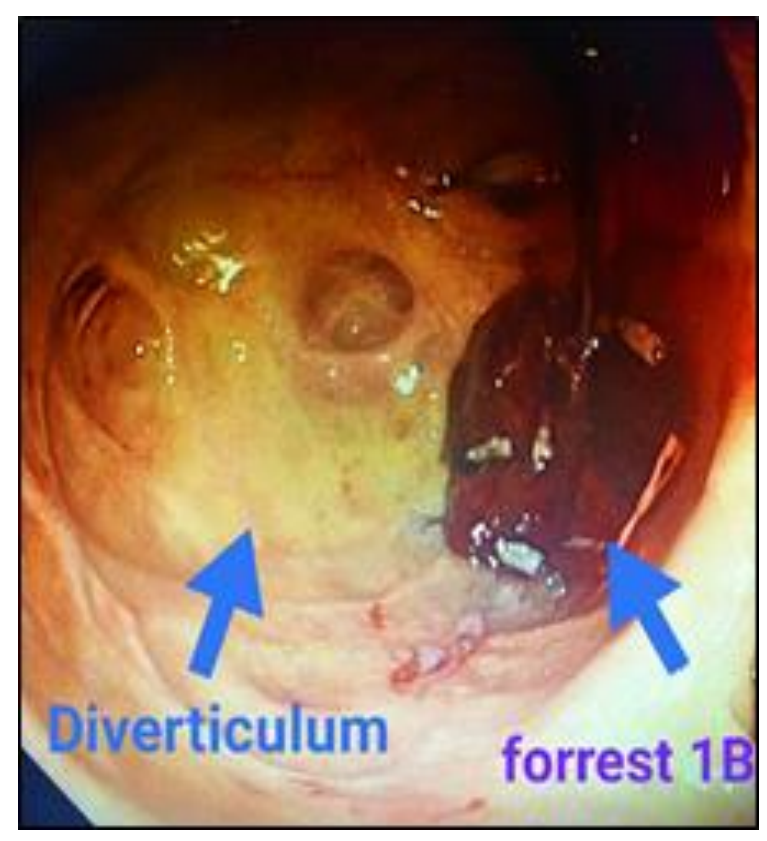

Figure 1: Showed the Presence of retroperitoneal free air on abdominal plain radiograph

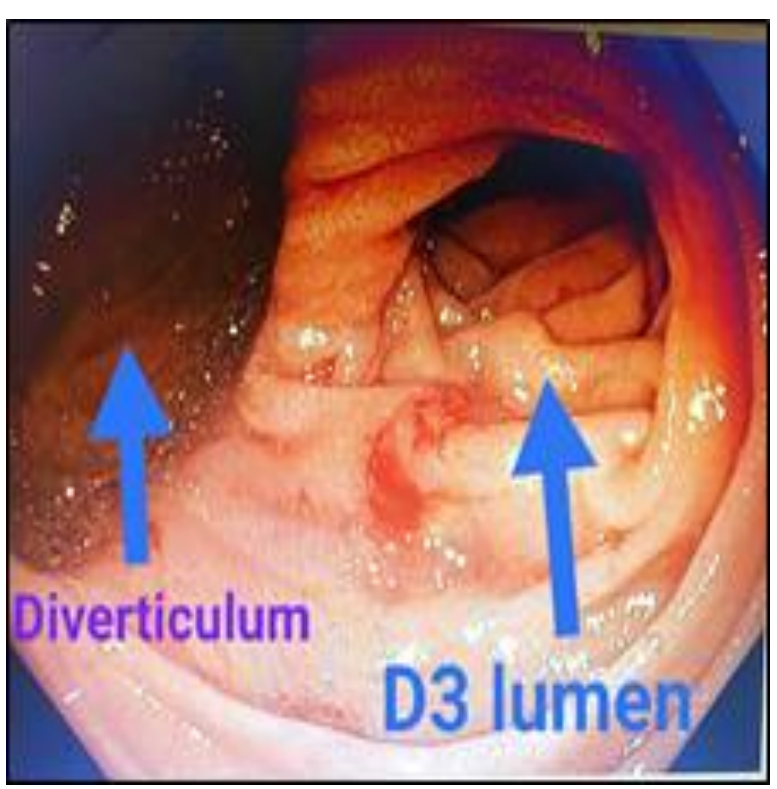

Figure 2: Showed the Presence of retroperitoneal free air on abdominal plain radiograph 


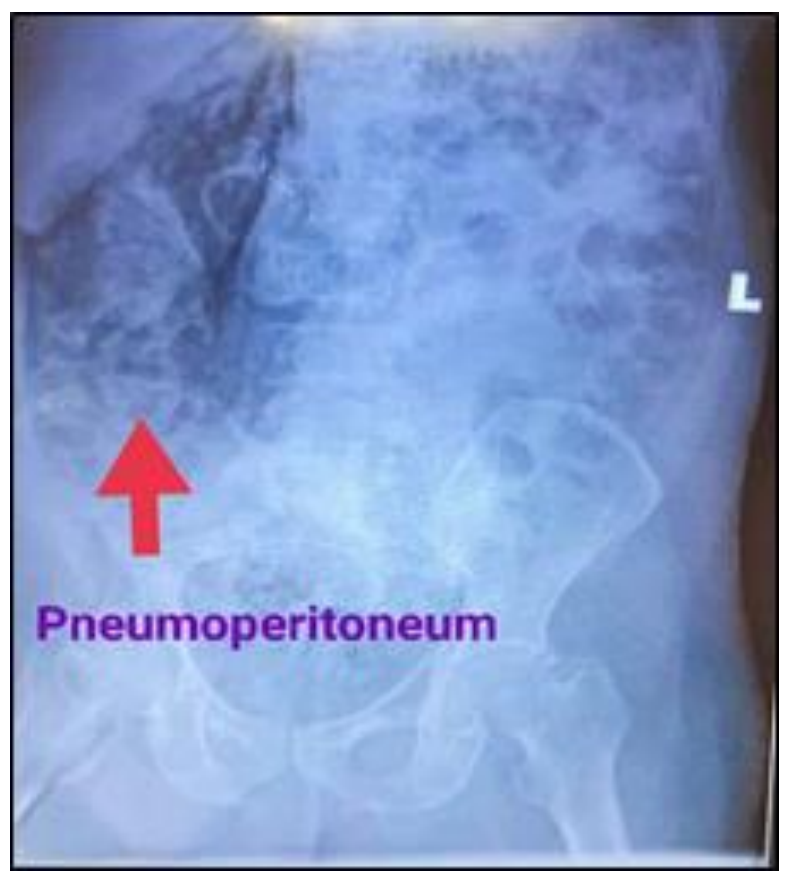

Figure 3: Showed the Presence of retroperitoneal free air on abdominal plain radiograph

\section{Discussion}

Duodenal diverticulum (DD) are commonest located in the second part of the duodenum about $60 \%$ (within 2 to $3 \mathrm{~cm}$ from ampulla of Vater). Followed by, third part of the duodenum about $30 \%$ and forth part of the duodenum about $8 \%$. Nearly $90 \%$ of diverticula are present on the medial surface (along the pancreatic or mesenteric border) of the duodenum [3]. In our patient, the DD was presence at third part of the duodenum.

DD perforation and bleeding is very rare. A duodenal perforation can be the result of ulceration, enterocoliths, blunt abdominal trauma, iatrogenic perforation during an Endoscopic Retrograde CholangioPancreaticography (ERCP).As in our case was the endoscopic hemostasis injection and hemoclips.

DD bleeding etiology is still unclear.However, hypothesis result of the peptic digestive process following food retention in the diverticulum subsequently causing distension and ischemic process at the duodenal diverticulum part and causing perforation and bleeding [6].

Most DD are asymptomatic and often vague presentations upon perforation, including acute onset of abdominal pain, nausea, vomiting, fever, or anorexia and steatorrhea due to duodeno-colonic fistulas.

In our patient, patient presented with upper gastrointestinal bleeding and during endoscopic hemostasis procedure noted iatrogenic perforation of DD.

Radiological investigation, an abdominal computed tomography (CT) is most sensitive tool to detect a duodenal diverticulum perforation. It reveal thickened bowel wall, mesenteric fat stranding, and an extraluminal, retroperitoneal collection of air or fluid [7]. In our case, as this was a district hospital we proceeded with a abdominal xray and showed presence of free retroperitoneal air.

Management of the perforated bleeding duodenum diverticulum can be operative or conservative treatment depending on patient condition. Success has been found with both conservative and operative treatment of perforated duodenal diverticulum depending on the comorbidities and stability of the patient [5]. Conservative treatment, which includes fasting,startingparentral feeding and broad spectrum antibiotics, has been successful in stable elderly patients and patients with comorbidities who are poor operative candidates. Due to the rareness of perforated duodenal diverticulum, surgical treatment guidelines are still lacking.Surgical treatment is recommended for patients who do not show rapid improvement with conservative treatment and unstable patients with signs of diffuse peritonitis due to perforation. The standard operative treatment option is diverticulectomy, followed by simple closure of the site [8]. Occasionally, simple intra-abdominal drainage can be performed at the site of abscess formation. However, if substantial duodenal or retroperitoneal inflammation is present, a more complex procedure such as duodenal diversion, pyloric exclusion, gastro-enteric anastomosis, tube duodenostomy, and segmental duodenal resection or even pyloruspreserving Whipple might be surgical consideration [8]. In our patient, in view of no clinical evidence of peritonism, absence of sepsis and patient is clinically stable, we successfully treated patient conservatively by keep nil by mouth and started on parentral nutritional support, intravenous antibiotics and serial abdominal examination.

\section{Conclusion}

We present a case of upper gastrointestinal bleeding from a D3 diverticulum with iatrogenic perforated duodenal diverticulum due to endoscopic hemostasisinjection. We treated this patient conservatively by keep nil by mouth and started on parentral nutritional support, intravenous antibiotics and serial abdominal examination. We advocate in duodenal diverticulum bleeding the application of endoscopic clips and injection should be use juridiously. In case of iatrogenic perforation of duodenum diverticulum due to endoscopic hemostasis can still be treated conservatively in stable, elderly patients with no signs of diffuse peritonitis and no clinical evidence of sepsis.

\section{References}

1. J. Glener, S. Poris, B. Foles, and R. Harmon. (2016). "Perforated duodenal diverticulum case report," International Journal of Surgery Case Reports. 29; 100-102.

2. Kansounet al. (2020). "Surgical approach for duodenal diverticulum perforation: A case report," International Journal of Surgery Case Reports. 76; 217-220. 
3. J. A. Degheili, M. H. Abdallah, A. A. Haydar, A. Moukalled, and A. H. Hallal. (2017). "Perforated Duodenal Diverticulum Treated Conservatively: Another Two Successful Cases," Case Reports in Surgery. 1-5.

4. V. Costa Simões, B. Santos, S. Magalhães, G. Faria, D. Sousa Silva, and J. Davide. (2014). "Perforated duodenal diverticulum: Surgical treatment and literature review," International Journal of Surgery Case Reports. 5(8); 547-550.

5. K. H. Kim and S. H. Park. (2018). "Conservative treatment of duodenal diverticulitis perforation: A case report and literature review," Open Access Emergency Medicine. 10; 101-104.
6. R. Andrea. (2013). "Perforated duodenal diverticulum, a rare complication of a common pathology: A seven-patient case series," World Journal of Gastrointestinal Surgery. 5(3); 47.

7. S. Song. (2015). "Management of Perforated Duodenal Diverticulum: Report of Two Cases," The Korean journal of gastroenterology = TaehanSohwagiHakhoe chi. 66(3); 159-163.

8. M. Moysidiset al. (2020). "The challenging diagnosis and treatment of duodenal diverticulum perforation: A report of two cases," BMC Gastroenterology. 20(1).
This work is licensed under Creative Commons Attribution 4.0 License

To Submit Your Article Click Here: Submit Manuscript
Ready to submit your research? Choose Auctores and benefit from:

$>$ fast, convenient online submission

$>$ rigorous peer review by experienced research in your field

$>$ rapid publication on acceptance

$>$ authors retain copyrights

$>$ unique DOI for all articles

$>$ immediate, unrestricted online access

At Auctores, research is always in progress.

Learn more auctoresonline.org/journals/journal-of-clinical-surgery-andresearch 